\title{
EL CINE BOLIVIANO SOBREVIVIENDO AL COVID-19: LA PERCEPCIÓN DE LOS REALIZADORES SOBRE LOS EFECTOS DE LA PANDEMIA
}

\section{Andrés Laguna-Tapia}

\section{RESUMEN}

En el presente artículo se busca describir el efecto que tuvo la pandemia en el sector audiovisual boliviano, en el primer semestre de 2020, un periodo agravado por múltiples factores, entre ellos, la crisis política e institucional desatada en octubre-noviembre de 2019, una baja cultura digital, una importante brecha digital y una realidad socioeconómica compleja. Este es un trabajo de naturaleza exploratoria y cualitativa, que principalmente recolectó la información a través de fuentes primarias. Es decir, a través de los testimonios de realizadoras, realizadores, productoras y productores de distintos lugares de Bolivia. La herramienta fundamental para la recolección de datos fue la entrevista semiestructurada, probablemente la metodología más utilizada en investigaciones de naturaleza cualitativa. Se concluye que, desde la perspectiva de los realizadores, los efectos de la pandemia sobre el audiovisual boliviano fueron agravados por la crisis política y por una deficiente gestión del gobierno de transición. Por otro lado, los procesos de transformación de los modos de producción, de distribución y de comercialización, acelerados por la pandemia, deben ser asumidos, repensados y asimilados desde el contexto boliviano, como, por ejemplo, el uso de plataformas de VOD. Finalmente, se constató una tendencia en los realizadores nacionales, creen que el cine boliviano debe comprometerse con la realidad social y con el diálogo con el otro.

Palabras Clave: Cine Boliviano, Covid-19, Realizadores Bolivianos, Percepción, Streaming, VOD.

DOI: $10.23881 /$ idupbo.020.2-11e 